\title{
Incidence of childhood diabetes in The Netherlands: a decrease from north to south over North-Western Europe?
}

\author{
G.J. Vaandrager ${ }^{1}$, G. J. Bruining ${ }^{2}$, F. J. Veenhof ${ }^{1}$ and N. M. Drayer ${ }^{3}$ \\ ${ }^{1}$ Netherlands Institute for Preventive Health Care/TNO, Leiden; ${ }^{2}$ Department of Paediatrics, Division of Endocrinology, \\ Erasmus University and University Hospital Rotterdam/Sophia Children's Hospital, Rotterdam; \\ ${ }^{3}$ Department of Paediatrics, Endocrine Unit, State University of Groningen, The Netherlands
}

Summary. The incidence of childhood diabetes (0-19 years of age) in The Netherlands, where there is no nationalized health-care system, was investigated retrospectively in the years 1978 to 1980 inclusive. The method chosen was a questionnaire among all Dutch paediatricians and internal physicians acting as consultants. Ascertainment was by the same questionnaire held separately among the large Dutch membership of the Dutch Diabetes Association, employing the capture-recapture census method for calculation. For paediatricians the ascertainment was $94 \%$, for specialists in internal medicine $75 \%$. Before correction for ascertainment 1271 children were registered in the two surveys. The ascertainment- corrected annual incidence was $10.95 / 100000$ for $0-19$-yearold children, lower than in any other ascertained survey in north-western Europe published so far. The male:female ratio was the same as in other studies and no local geographical differences were found. Seasonal variation was absent in children $0-10$ years old in the month the first insulin injection was administered. The data support the influence of unknown exogenous factors associated with the clinical onset of childhood diabetes.

Key words: Juvenile diabetes mellitus, epidemiology, child, seasonal variation.
In the past decade incidence-rates of childhood diabetes $(0-14$ or $0-19$ years of age) have been determined in all Scandinavian countries [1-4] and parts of the United Kingdom [5]. In each of these studies a high ascertainment rate was possible by virtue of the health-care system, giving access to drug-registry and hospital files. In The Netherlands there is no nationalized health-care system; however there is an effective registration system.

We decided to conduct a retrospective survey on the incidence of insulin dependence among all diabetic children in The Netherlands from $0-19$ years of age, for 3 years from 1978 to 1980 inclusive. The Netherlands national register counted 4.46 million youngsters from $0-19$ years at that time, of whom $6.1 \%$ were born to first-generation immigrants. In the health-care system, only paediatricians and specialists in internal medicine treat insulin dependence in minors, and both types of specialists act as registered consultants.

\section{Methods}

A questionnaire was sent to all consultant paediatricians and consultants in internal medicine to obtain data on children diagnosed diabetic between 1978 and 1981 . The questions asked sought only the ini- tials of the child's name, sex, date of birth, date of the first insulin injection and residence at that time (no attempt was made to identify children of immigrants or of non-Caucasoid background). The questionnaire was sent to 660 consultant physicians in internal medicine and 263 consultant paediatricians in the 181 general hospitals, and to a contact person in each of the eight internal medicine and seven paediatric university clinics. including residential care centres. All the paediatricians, university clinics and residential care centres, and 97\% of the physicians in internal medicine, responded between February and September 1981. The same information was obtained separately from the Dutch Diabetes Association, to verify the data obtained from the specialists.

\section{Ascertainment}

In the monthly periodical sent to all 35000 members $(2.44$ per 1000 inhabitants, with a range from $1.87-3.26$ per 1000 over the 11 provinces in The Netherlands), patient-members were requested to submit the same information of the Diabetes Association. The membership of the Diabetes Association is high as members can obtain treatment materials at retail prices. The request to the members was published when $80 \%$ of the specialist responses had been obtained (April 1981). In addition to the questions mentioned above, the members were also asked who was the child's doctor; all answers contained either a consultant paediatrician or a consultant in internal medicine, confirming that all diabetic children were treated by such specialists. Furthermore, all doctors thus reported were present on our mailing lists. The paediatricians reported 856 children and the internal physicians 415 , making a total of 1271 youngsters aged $0-19$ years in whom insulin treatment was initiated and continued in 1978-1980. 
Table 1. Cases of insulin-dependent diabetes reported, by type of specialist, patient/members of the Diabetes Association, age in years and ascertainment rate

\begin{tabular}{|c|c|c|c|c|c|}
\hline & \multicolumn{3}{|c|}{ Number of cases reported by: } & $\begin{array}{l}\text { Rate of } \\
\text { ascertainment } \\
(\%)\end{array}$ & $\begin{array}{l}\text { Significance of } \\
\text { difference in } \\
\text { ascertainment rate }\end{array}$ \\
\hline \multicolumn{6}{|l|}{ Type of specialist } \\
\hline Paediatrician & 856 & 206 & 194 & 94 & \multirow[t]{2}{*}{$p<0.001$} \\
\hline Internal physician & 415 & 99 & 74 & 75 & \\
\hline \multicolumn{6}{|l|}{$\begin{array}{l}\text { Age on starting } \\
\text { insulin (years) }\end{array}$} \\
\hline $0-4$ & 179 & 50 & 49 & 98 & \multirow[t]{4}{*}{$p<0.02$} \\
\hline $5-9$ & 323 & 90 & 80 & 89 & \\
\hline $10-14$ & 463 & 99 & 87 & 88 & \\
\hline $15-19$ & 306 & 66 & 52 & 79 & \\
\hline
\end{tabular}

Table 2. The 3-year incidence and the incidence per 100,000 inhabitants per year according to sex and age group, after correction for ascertainment

\begin{tabular}{rrrlrl}
\hline $\begin{array}{l}\text { Age } \\
\text { (years) }\end{array}$ & $\begin{array}{r}\text { Number Standard } \\
\text { deviation }\end{array}$ & $\begin{array}{l}\text { Mean } \\
\text { population } \\
\text { over the } \\
\text { 3 years }\end{array}$ & $\begin{array}{l}\text { Incidence } \\
\text { per 100,000 } \\
\text { per year }\end{array}$ & $\begin{array}{l}\text { Standard } \\
\text { deviation }\end{array}$ \\
\hline \multicolumn{7}{c}{ Boys } \\
$0-4$ & 102 & 3.4 & 456,327 & 7.45 & 0.25 \\
$5-9$ & 202 & 11.9 & 564,636 & 11.91 & 0.70 \\
$10-14$ & 261 & 11.2 & 625,878 & 13.88 & 0.60 \\
$15-19$ & 228 & 16.5 & 633,133 & 11.98 & 0.87 \\
$0-19$ & 790 & 22.8 & $2,279,974$ & 11.55 & 0.33 \\
\hline Girls & & & & & \\
$0-4$ & 82 & $(-)^{\mathrm{a}}$ & 434,746 & 6.29 & $(-)^{\mathrm{a}}$ \\
$5-9$ & 164 & 5.9 & 539,960 & 10.11 & 0.36 \\
$10-14$ & 266 & 15.9 & 597,359 & 14.84 & 0.89 \\
$15-19$ & 163 & 16.8 & 605,746 & 8.95 & 0.92 \\
$0-19$ & 676 & 24.3 & $2,177,811$ & 10.35 & 0.37 \\
\hline
\end{tabular}

ascertainment 100\%

From the Diabetes Association, 305 complete responses were obtained, of which 268 were found also in the specialists' responses. This implied a reporting rate from the Diabetes Association of $21 \%$, and an ascertainment rate by the questionnaire among the specialists of $88 \%$ of the total number of patients. For 1978 , the ascertainment rate was $85 \%$, for $197984 \%$ and for $198093 \%$ (no significant difference).

\section{Calculation of incidence estimates}

The method used for the estimation of the corrected number of new patients and its confidence limits (expressed as standard deviation in Table 2) was based on the capture-recapture census described by Bishop et al. [6] and Sekar and Deming [7]. A premise with this method is that the response of the patient-members of the Diabetes Association was independent of that of the specialists. The homogeneity of each file (physicians and patient/members of the Diabetes Association) was tested by comparing ascertainment rates found with age, sex, kind of specialist, grade of urbanization of living place [8], month of the first insulin injection and province of living at that time. No significant differences were found except for age and kind of specialist. However, both the degree of completeness of the files and the age of the patients were dependent on the factor "kind of specialist". The

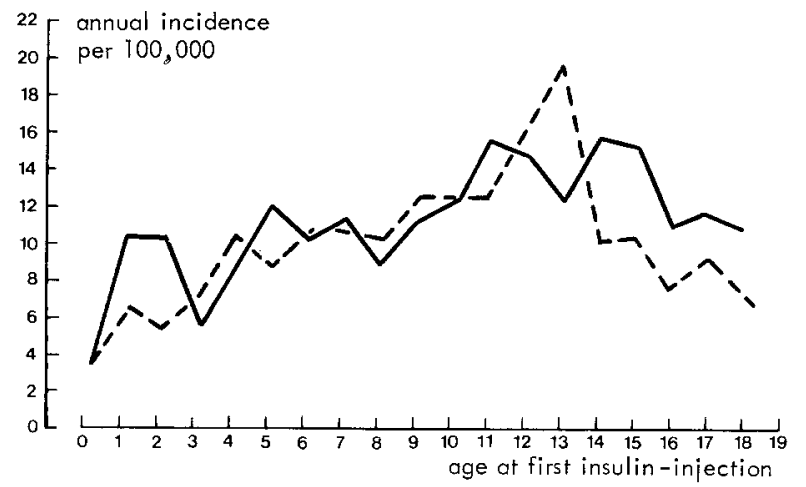

Fig. 1. Annual incidence of diabetes in children versus age at start of insulin treatment over 3 years. $-=$ boys $(n=682) ;---=$ girls $(n=589)$

data were divided according to the two subgroups of specialists, to give the overall incidence rate. The two sets of data were multiplied by the reciprocal of their ascertainment percentages and then added.

\section{Statistical analysis}

Further statistical tests used were a modification of the Kolmogorov/ Smirnov test [9], for seasonal variations and two-way $\chi^{2}$ test for other comparisons. The level of significance chosen was $p<0.05$.

\section{Results}

Figure 1 depicts the incidence in children grouped by sex and age at the first insulin injection. The male: female sex ratios in the different age groups were: $0-4$ years: $1.18,5-9$ years: $1.18,10-14$ years: 0.94 , $15-19$ years: 1.34 ; and $0-14$ years: $1.05 ; 0-19$ years: 1.12 .

Ascertainment by paediatricians (94\%) was considerably more complete than that by internal physicians (75\%) (Table 1). For the age-groups 0-4, 5-9, 10-14 and 15-19 years the paediatricians' ascertainment rates were respectively $98,90,97$ and $100 \%$, while those of the internal physicians were 67,70 and $77 \%$. The progressive 
decrease in ascertainment rate with age was significant $(p<0.02)$.

The observed incidence rates classified by sex and age, and the standard deviation of the method of estimation are shown in Table 2 . The ascertainment-corrected incidence was $10.95 \cdot 10^{-5} \cdot$ year $^{-1}$ for $0-19$ years and $11 \cdot 10^{-5} \cdot$ year $^{-1}$ for $0-14$ years. The $95 \%$ confidence intervals were $10.47-11.43$ and $10.64-11.56$ respectively for these age groups.

The range of the differences between Dutch provinces was $8.9-13.7 \cdot 10^{-5} \cdot$ year $^{-1}$ in children from $0-19$ years of age. These differences were not statistically significant.

Rural areas, urbanized municipalities and large municipalities had similar incidence rates of $11.61,10.52$ and $11.14 \cdot 10^{-5} \cdot$ year $^{-1}$, respectively. The distribution of the months of the year in which the first insulin injection was administered revealed no statistically significant differences for 0-4-year-old, nor for 5-9-year-old children. In the age groups $10-14$ and $15-19$ years, a seasonal influence was present with the incidence rates higher in the winter months than in the summer months ( $p<0.05$ and $p<0.01$, respectively). When the seasonal variation was studied for the 3 years separately, these differences were significant for 1978 and 1980, but not for 1979.

\section{Discussion}

The annual incidence found in the present study over the whole of The Netherlands (14.3 million inhabitants) was lower than that found in any other ascertained survey in western Europe conducted over the same period. The sex distribution and the trends in age of initiation of insulin treatment were very similar to those found in other studies. The present survey found no seasonal variation in the onset of clinical diabetes in children younger than 10 years of age. No significant differences in incidence were found with regard to either the distribution over the provinces of The Netherlands or the degree of urbanization. This is perhaps not surprising as truly rural areas are rare in densely-populated Netherlands.

Given the limitations imposed by The Netherlands health-care system on the drug-registry for ascertainment methods, the capture-recapture census method was chosen to calculate the confidence limits of the incidence found by two separate questionnaires. The method used facilitated examination of the largest childhood population so far studied, the disadvantage being the ascertainment rate of only $79 \%$ for the children aged 15-19 years. For younger children almost all responses were obtained before the survey among members of the Dutch Diabetes Association, and the ascertainment rate for that age-cohort was $90 \%$.

The difference in ascertainment rate between paediatricians and specialists in internal medicine was prob- ably due to the much higher density of newly-diagnosed children seen by the former. Over the 3 years of the study there were 3.25 cases per reporting paediatrician $\left(\frac{856}{263}\right)$, and 0.62 cases per adult physician $\left(\frac{415}{660}\right)$. It was found that $837(94 \%)$ of the newly-diagnosed children aged $0-14$ years were reported by consultant paediatricians, and $287(87 \%)$ of those aged 15-19 years were reported by consultant internal physicians. These percentages indicate a referral pattern sharply dependent on the age of the newly diagnosed diabetic children in the Dutch health-care system.

The incidence found for children $0-14$ years of age was little more than one-third that found in Finland [1] or one-half that in Sweden [2] and Norway [3], and also lower than that reported from Denmark, excepting children aged $0-5$ years [4]. As emphasised by Christau et al. [10], it is very difficult to compare incidence rates, even with high ascertainment rates, if different methods are used. Yet it is difficult to conceive that ascertainment methods alone could explain differences in incidence of such magnitude. Genetic variation is not a likely explanation as childhood diabetes is associated with the same genotypes of the major histocompatibility complex in The Netherlands as in other north-western European countries [11]. With time, by comparing yearly incidence rates, remarkable changes in incidence rates have been noted, as well as twofold differences between regions of the same country [1-5]. However the numbers of newly diagnosed children involved in such analyses were small [10].

In north-western European countries the incidence of childhood diabetes (age 0-14 years) appears to have increased over recent decades $[1,5,12]$. In The Netherlands the prevalence of diabetes among army conscripts at age 18 years increased gradually from 0.99 per 1000 in 1960 to 1.72 per 1000 in 1980 , indicating a similar trend. The incidence found in the present survey adds another suggestion: that of a possible north-south gradient over north-western Europe. This suggestion is by no means proven but reinforces the importance of exogenous factors involved in the clinical onset of childhood diabetes.

Acknowledgements. We thank the members of the Dutch Diabetes Association for their enthusiastic cooperation, and the paediatricians and the internists of The Netherlands for their time and help. The Ministry of Health gave valuable advice and the division for medical examinations of army conscripts of the Ministry of Defense gave data 1960-1979. The support of the Stichting Diabetes Research Fonds and of Nordisk Nederland, part of Nordisk Insulin Laboratories. Denmark, is gratefully acknowledged.

\section{Literature}

1. Reunanen A, Åkerblom HK, Käär ML (1982) Prevalence and tenyear (1970-1979) incidence of insulin-dependent diabetes mellitus in children and adolescents in Finland. Acta Paediatr Scand 71: 893-899

2. Dahlquist $G$, Gustavsson KH, Holmgren $G$, Hägglof B, Larsson 
Y, Nilsson KO, Samuelsson G, Sterky G, Thalme B, Wall S (1982) The incidence of diabetes mellitus in Swedish children $0-14$ years of age: a prospective study 1977-1980. Acta Paediatr Scand 71: 7-14

3. Joner G, Søvik O (1981) Incidence, age at onset and seasonal variation of diabetes mellitus in Norwegian children, 1973-1977. Acta Paediatr Scand 70: 329-335

4. Christau B, Kromann H, Christy M, Andersen OO, Nerup J (1979) Incidence of insulin-dependent diabetes mellitus (0-29 years at onset) in Denmark. Acta Med Scand [Suppl] 624: 54-60

5. Patterson CC, Thorogood M, Smith PG, Heasman MA, Clarke JA, Mann JI (1983) Epidemiology of Type 1 (insulin-dependent) diabetes in Scotland 1968-1976: evidence of an increasing incidence. Diabetologia 24: 238-243

6. Bishop YMM, Fineberg SE, Holland PW (1978) Estimating the size of a closed population. In: Bishop YMM, Fineberg SE, Hol land PW (eds) Discrete multivariate analysis. Massachusetts Institute of Technology, Cambridge, pp 229-256

7. Sekar CC, Deming WE (1949) On a method of estimating birth and death rates and the extent of registration. Am Statist Ass J 44: 101-115

8. Centraal Bureau voor de Statistiek (1964) Typologie van de Nederlandse gemeenten naar urbanisatie-graad. W. de Haan, Zeist, the Netherlands
9. Freedman LS (1979) The use of a Kolmogorov-Smirnov type statistic in testing hypotheses about seasonal variation. $\mathbf{J}$ Epidemiol Community Health 33: 223-228

10. Christau B, Åkerblom H, Joner G, Dahlquist G, Ludvigsson J, Nerup J (1981) Incidence of childhood insulin-dependent diabetes mellitus in Denmark, Finland, Norway and Sweden: a workshop report. Acta Endocrinol [Suppl] Copenh 245: 68-80

11. De Jongh BM, Bruining GJ, Schreuder GMTh, Schuurman RKB, Radder JK, van Loghem E, Meera Khan P, Hauptmann G, van Rood JJ (1984) HLA and GM in insulin-dependent diabetes in The Netherlands: report on a combined multiplex family and population study. Hum Immunol (in press)

12. Ustvedt HJ, Olsen E (1977) Incidence of diabetes mellitus in Oslo, Norway, 1956-1965. Br J Prev Soc Med 31: 251-257

Received: 5 July 1983

and in revised form: 4 June 1984

Dr. G.J. Vaandrager

Netherlands Institute for Preventive Health Care

Wassenaarseweg 56

2300 AC Leiden

The Netherlands 